\title{
EL PROBLEMA NACIONAL Y COLONIAL DEL PERU EN EL CONTEXTO DE LA GUERRA DEL PACIFICO*
}

\author{
Heraclio Bonilla**
}

Patricio Lynch, el Comandante en Jefe de la fuerza expedicionaria chilena, visitaba en compañla del Almirante francés Du Petit Thouars uno de los hospitales de Lima, luego de la batallas de San Juan y Miraflores que provocaron la ocupación de la ciudad. Lynch, tratando de explicar las causas de la derrota peruana al almirante francés, se acercó a dos heridos peruanos y luego de dirigirles palabras consoladoras, les preguntó separadamente:

"-Y ¿para qué tomó Ud. parte en estas batallas?

Yo, le contestó el uno: "por don Nicolás"; y el otro: "por don Miguel".

Don Nicolás, era Piérola; don Miguel, el Coronel Iglesias. Dirigió luego la misma pregunta a dos heridos del ejército chileno y ambos le respondieron con profunda extrañeza:

" „Por mi patria, mi General!".

Y Lynch, volviéndose a Du Petit Thouars, le dijo:

La documentación que sustenta el razonamiento expuesto en este trabajo proviene esencialmente del National Archive de Washington y del Foreign Office de Londres. Mi nombram iento como Visiting F ellow del Woodrow Wilson International Center For Schólards en el segundo semestre de 1974 y del Centre for Latin American Studies de la Universidad de Liverpool entre enero y marzo de 1977, posibilitó mi acceso a estos repositorios. Algunas de las ideas que aquí se desarrollan fueron discutidas en los seminarios sobre América Latina de las Universidades de Liverpool, Cambridge y Londres y una primera versión de este texto fue presentada como ponencia al II Encuentro de Historiadores Latinoamericanos realizado en Caracas entre el 20 y el 26 de marzo de 1977. Quisiera expresar mi agradecimiento a los profesores James $H$. Billington, Harold Blakemore, David Brading, John Fisher, Eric J. Hobsbawn, John Lynch, Rory Miller y Clifford, T. Smith por la asistencia y los comentarios que me ayudaron a precisar mi pensamiento. Es de mi entera responsabidad si pese a ello persisten aún algunos errores. La versión integral inglesa, en fina traducción del profesor Eric. J. Hobsbawn, fue publicado en Past and Present Oxford, 1978, No. 81, pp. 92-188.

El autor es miembro del Instituto de Estudios Peruanos y Profesor en el Departamento de Economía de la Universidad Católica del Perú. 
"Por eso hemos vencido. Unos se batían por su patria, los otros por don fulano de taP"'.

Cuarenta años más tarde, el escritor peruano Enrique López Albújar en un hermoso cuento, a medio camino entre la realidad y lo imaginario, describe el diálogo sostenido entre el indio Aparicio Pomares y los comuneros de Obas, en Huánuco, buscando el primero despertar la resistencia de estos campesinos en contra de la ocupación chilena:

"-Quizás ninguno de Uds. se acuerde ya de mi. Soy Aparicio Pomares, de Chupán, indio como ustedes, pero con el corazón muy peruano. Los he hecho bajar para decirles que un gran peligro amenaza a todos estos pueblos, pues hace quince días que han llegado a Huánuco como doscientos soldados chilenos. $Y$ isaben Uds. quienes son esos hombres? Les diré. Esos son los que hacen tres afos han entrado al Perú a sangre y fuego. Son supaypa-huachashgan y es preciso exterminarlos. Esos hombres incendian los pueblos por donde pasan, rematan a los heridos, fusilan a los prisioneros, violan a las mujeres, ensartan en sus bayonetas a los niffos, se meten a caballo en las iglesias, roban las custodias y las alhajas de los santos y después viven en las casas de Dios sin respeto alguno, convirtiendo las capillas en pesebreras y los altares en fogones. En varias partes me he batido con ellos. (....)

¿Y por qué chilenos hacen cosas con pinumos? -interrogó el cabecilla de los Obas- ¿no son los mismos mistts?

-No, esos son otros hombres. Son mistis de otras tierras, en las que no mandan los peruanos. Su tierra se llama Chile.s.

¿Y, por qué pelean con los piruanos? - volvió a interrogar el de Obas.

-Porque les ha entrado codicia por nuestras riquezas, porque saben que el Perú es muy rico y ellos muy pobres. Son unos piojos hambrientos.

El auditorio volvió a estaliar en carcajad as. Ahora se explicaban porqué eran tan ladrones aquellos hombres: tenían hambre. Pero el de Obas, a quien la frase muestras riquezas no lo sonab a bien, pidió una explicación.

-Por qué has dicho Pomares nuestras riquezas? ¿Nuestras riquezas son, acaso, las de los mistis? ¿Y qué riquezas tenemos nosotros? Nosotros sólo tenemos carneros, vacas, terrenitos y papas y trigo para comer. ¿Valdrán todas estas cosas para que esos hombres vengan de $\tan$ lejos a querernoslas quitar?

- Les hablaré más claro, replicó Pomares. Ellos no vienen ahora por nuestros ganados, pero si vienen por nuestras tierras que están allá en el Sur. Primero se agarrarán esas, después se agarrarán las de acá. ¿Qué se creen Uds.? en la guerra elque puede más le quita todo al que puede menos.

Pero las tierras del Sur son de los mistis. son tierras con las que nada tenemos que hacer nosotros - argulló nuevamente el obasino- ¿Qué tienen que hacer las tierras de Pisagua, como dices tú, con las de Obas, Chupán, Chavinillo, Pachas y las demás? 
-Mucho. Uds. olvidan que en esas tierras está el Cuzco, la ciudad sagrada de nuestros abuelos. Y decir que el misti chileno nada tiene que hacer con nosotros es como decir que si manana, por ejemplo, unos bandoleros atacaran Obas y quemaran unas cuantas cosas, los moradores de las otras, a quienes no se les hubiera hecho dafio, dijeran que no tenian que meterse con los bandoleros ni porqué persegurirlos. ¿Así piensan Uds. desde que yo falto aquir? (...)

¿Acaso les tendrán Uds. miedo? Que se levante el que tenga miedo al chileno (....)

Pero el viejo Cusasquiche, que era el jefe de los de Chavinillo, viejo de cabeza venerable y mirada de esfinge, dejando de acariciar la escopeta que tenía sobre los muslos, dijo, con fogosidad impropia de sus años:

-Tú sabes bien, Aparicio, que entre nosotros no hay cobardes, sino prudentes. El indio es muy prudente y muy sufrido y cuando se le acaba la paciencia embiste, muerde y despedaza. Tu pregunta no tiene razón. En cambio, yo te pregunto, ¿por qué vamos a hacer causa. común con mistis pirumos? Mistis ptruanos nos han tratado siempre mal. No hay affo en que esos hombres no vengan por acá y nos saquen contribuciones y nos roben nuestros animales y también nuestros hijos, unas veces para hacerlos soldados y otras para hacerlos pongos ¿Te has olvidado de esto, Pomares? -No, Cusasquiche. Cómo voy a olvidar si conmigo ha pasado eso. Hace cuatro años queme tomaron en Huánuco y me metieron al ejército y me mandaron a pelear al sur con los chilenos. Y fui a pelear llevando a mi mujer y a mis hijos colgados del corazón. ¿Qué iba a ser de ellos sin mi? Todos los días pensaba lo mismo y todos los días intentaba desertarme. Pero se nos vigilaba mucho. Y en el sur, una vez que supe por el sargento de mi batallón por qué peleábamos, y ví que otros compañeros que no eran indios como yo, pero seguramente de mi misma condición, cantaban, bailaban y refan en el mismo cuartel, y en el combate se batian como leones, gritando ;Viva el Perú! y retando al enemigo, tuve vergüenza de mi pena y me resolví a pelear como ellos. ¿Acaso ellos no tendrían tambien mujer y guagtuas como yo? Y como of que todos se llamaban peruanos, yo también me llamé peruano. Unos, peruanos de Lima; otros peruanos de Arequipa; otros peruanos de Tacna. Yo era peruano de Chupán... de Huánuco. Entonces perdoné a los mistis peruanos que me hubieran metido al ejército, en donde aprendf muchas cosas. Aprendf que Perú es una nación y Chile otra nación; que el Perá es la patria de los mistis y de los indios; que los indios vivimos ignorando muchas cosas porque vivimos pegados a ruestras tierras y despreciando el saber de los mistis siendo asi que los mistis saben más que nosotros. $Y$ aprendi que cuando la patria está en peligro, es decir, cuando los hombres de otra nación la atacan, todos sus hijos deben defenderla. Ni más ni menos que lo que hacemos por acá cuando alguna comunidad nos ataca. ¿Que los mistis peruanos nos tratan mal? iVerdad! Pero peor nos tratarían los mistis chilenos. Los peruanos son, al fin, hermanos nuestros; los otros son nuestros enemigos. Y entre unos y otros elijan Uds". ${ }^{2}$

2 Enrique López Albújar, "El hombre de la band era", en Cuentos Andinos. Lima edición, Bditorial Juán Mejła Baca, p. 57.68. 
Tanto el contenido del diálogo del Coronel Patricio Lynch, como el del comunero Aparicio Pomares se refiere a las actitudes asumidas por segmentos importantes de las clases populares del Perú durante la llamada Guerra del Pacífico, es decir, el conflicto militar que opuso a Chile y Perú entre 1879 y 1883. Estas actitudes son, evidentemente, síntomas. Apenas indicios que revelan y que traducen un problema capital: la dimensión social de la Guerra del Pacífico, o, si se quiere, el desdoblamiento de una guerra nacional en un conflicto interno que fue a la vez étnico y de clase. Esta guerra, como es bien conocido, terminó con el desastre militar, económico y político de la clase dirigente peruana. Pero al margen de esta tragedia, el proceso mismo de la guerra brinda al historiador una oportunidad excepcional para probar la solidez de los supuestos nacionales con los que el Perú se había convertido en República sesenta años antes. Nada mejor que una situación de crisis para examinar los fundamentos de una sociedad y las motivaciones del comportamiento de sus hombres. $Y$ es justamente la exploración de este problema lo que se quiere intentar aquí. Pero antes de emprenderla es conveniente precisar con el mayor rigor posible el alcance y el significad o del análisis que se propone.

¿Por qué, en primer lugar, exploración? Por la simple razón de que la Guerra del Pacifico es un proceso, al igual que otros, todavia insuficientemente estudiado ${ }^{3}$. Es necesario aún una cuidadosa investigación sobre los diferentes aspectos de la Guerra del Pacífico antes de establecer conclusiones o redactar una síntesis definitiva. La comprobación de esta carencia no está con tradicha por la existencia de una densa literatura nacional sobre la Guerra del Pacffico, escrita en los tres países con fines apologéticos o exculpatorios y con una utilidad científicamente nula. Lo que aquí se intenta, por consiguiente, más que escribir la historia completa de la guerra en tre Perú y Chile, es apenas abrir y sustentar una perspectiva de análisis para una de las dimensiones de la Guerra del Pacífico.

¿Por qué, en segundo lugar, privilegiar la dimensión social del conflicto en lugar de otros? Es curioso comprobar, por lo menos en el Perú, que la alternativa elaborad a frente a la interpretación oficial de la Guerra del Pacífico se reduce a la exposición de una tesis que puede llamarse de la conspiración extranjera. En sus términos más simples ella sostiene que los actores directos en la guerra en realidad fueron sino meras sombras, en el mejor de los casos

3 Entre los trabajos sobre la Guerra del Pacifico merecen mencionarse, Gonzalo Bulnes, Guerra del Pacífico, Santiago 1911-1919, 8 vols; A Blanlot Holley Histo ria de la Paz entre Chile y Perú, 1879.1882, Santiago, 2a. edición, 1910 M.F. Paz Soldán, Narración Histórica de la Guerra de Chile contra el Perú y Bolivia, Buenos Aires 1924; Sir Clements R. Markham, The War Between Peru and Chile, 1879-1882, Londres 1882; Tomaso Caivano, Historia de la Guerra de América entre Chile, Perú y Bolivia Iquique 1904; W.J. Dennis, Tacna and Arica: an account of the Chile-Peru 
simples marionetas cuyos hilos fueron indistintamente manejados desde Europa, es decir, Inglaterra y Francia, y desde los Estados Unidos. Esta fantasmagórica interpretación de la historia nacional es correcta en su intención, en la medida en que trata de situar un conflicto nacional dentro de una perspectiva más amplia, pero es errada en su análisis y desprovista de la evidencia suficiente que sustente adecuadamente sus afirmaciones. A este respecto caben aquí sólo dos disgresiones marginales.

La Guerra del Pacífico estalla en un momento que corresponde a lo que Lenin denominara al tnicio del imperialismo, es decir, una etapa caracterizada por sustantivas modificaciones en la estructura interna de las potencias europeas y en las modalidades de su expansión ultramarina. Este solo hecho justifica ampliamente la necesidad de examinar el papel de las fuerzas internacionales en el desencadenamiento, en el proceso y en la conclusión de la Guerra del Pacífica. Pero este examen, a su vez, supone distinguir un doble nivel de análisis: el de la política pública de los diferentes Estados y el de la polftica privada de las diferentes firmas que tuvieron el control de los principales recursos en Bolivia, Chile y el Perú. Sobre lo primero, la política pública, y el caso de Inglaterra, la principal potencia económica del momento, el profesor V.G. Kieman escribió hace 25 años un documentado artículo cuya principal conclusión parece indiscutible hasta el momento. Kiernan refiriéndose a lo expresado por el Secretario del Departamento de Estado norteamericano en 1882, que: "es un perfecto error hablar de esto como una guerra chilena contra el Perú. Es una guerra inglesa contra el Perú, con Chile como su instrumento", escribió lo siguiente:

"Pocas de las vastas consecuencias de la guerra podfan haber sido previstas cuando estallo; hecho que contradice la idea de Blaine de que esta era una "guerra inglesa". En la medida en que sus sospechas se refieren al capital británico establecido en los yacimientos salitreros chilenos, ahr debe quedar - al igual que en problemas análogos- un elemento de duda. Este capital tuvo estrechas relaciones con los intereses políticos y financieros chilenos, y a través de ellos pudo ejercer subrepticiamente una influencia del tipo que tiende a dejar pequeños rastros positivos de su actividad. El veredicto legal escocés de "no probado" puede ser aquí el más idóneo. La sospecha de Blaine, sin embargo, va más lejos, al conjunto de los intereses

Boundary Dispute and the Arbitration of the United States, New Haven 1931; Edmundo Civati Bernasconi, Guerra del Pacifico, Bs. As. 1946 William F. Sater, The Heroic Image in Chile, Los Angeles 1973; y, sobre todo, V.G. Kieman, "Foreign Interest in the War of the Pacific", en Hispanic American Historical Review XXXV (1955) pp. 14.36. 
británicos y al gobierno británico como su representante, y aquí el veredicto sólo puede ser "no culpable". 4

El rol de las diferentes firmas extranjeras en el origen y en el proceso de la guerra, por otra parte, es todavía absolutamente desconocido. Es el análisis de la documentación privada de los varios grupos de bondholders, de Dreyfus, de los propietarios de los yacimientos de salitre, de las casas comerciales, de los bancos, así como el de su correspondencia con los gobiemos, o fracciones de gobierno, de Chile, Perá y Bolivia que permitirá alguna vez su esclarecimiento. A condición de evitar pensar ingenuamente que el capital y sus agentes extranjeros apostaron de una vez y para siempre en favor o en contra de uno de los beligerantes. Una experiencia de cerca de 60 años en sus relaciones con la América Latina, después de todo, los inmunizó contra semejante audacia ${ }^{5}$.

Lo que este ensayo provisorio intenta, en cambio, es examinar la dimensión social de la Guerra del Pacífico. Este énfasis deriva del convencimiento de que tanto el proceso como los efectos producidos por la Guerra del Pacífico se explican mejor por un adecuado conocimiento de la estructuración interna de la sociedad peruana y de las manifestaciones que, al compás del conflicto se produjeron en su seno.

Aparentemente, el origen y el proceso militar de la Guerra del Pacifico son bastante conocidos. En el Atacama boliviano existran importantes yacimientos de salitre, que eran explotados por capitales chilenos y británicos. Un largo conflicto limítrofe entre Chile y Bolivia sobre el control de esta zona condujo a la Convención de 1872 y al Tratado de 1874 . Por la primera se reconocía como límite de ambos territorios al paralelo 24 'S, mientras que por el art. IV del Tratado, Bolivia se comprometía a no aumentar en 25 affos los impuestos a las empresas chilenas que operaban entre el paralelo $23^{\prime}$ y $24^{\prime}$ del territorio boliviano. Este Tratado no fue ratificado por el Congreso boliviano, y más bien, el 14 de febrero de 1878 el gobierno boliviano estableció un nuevo impuesto de diez centavos por cada quintal de salitre exportado desde 1874. La respuesta

4 V.G. Kiernan. "Foreign Interest in the War of the Pacific" en HHAR, XXXV (1955), pp. 35-36.

5 La Guildhall library de Londres conserva la documentación de Anthony Gibbs and Sons Ltd, es decir, de los "merchantbankers" que ejercieron lacomercialización del guano del salitre. La lectura y el análisis de estos papeles es esencial para entender el rol del capital privado en la Guerra del Paćffico. Véase particularmente, L. 64.22/MS 11,$120 ; 11,121 ; 11,122 ; 11,123 ; 11,124 ; 11,126 ; 11,470$ (vols. $3,4,5,7$ ); 11,471 (vols. 7-18); y 11,472 (vols. 1 al 4). 
chilena fue la ocupación militar del desierto de Atacama exactamente un año más tarde. El Perú, ligado a Bolivia desde 1873 por un "tratado secreto" de defensa mutua trató, en un primer momento, de mediar en el conflicto, pero ante su negativa de declararse neutral fue envuelto en él desde el 5 de abril de $1879^{6}$.

La descripción del proceso militar es igualmente simple. Luego de la ocupación chilena de Atacama, la guerra virtualmente se redujo al conflicto militar entre Peń y Chile. Sus principales fases fueron en parte el resultado de las imposiciones geográficas. Dada la distancia entre los centros de poder y la dificultad de las comunicaciones terrestres, la guerra fue en un primer momento marítima. La batalla de Angamos (8 de octubre de 1879), en este contex to, sancionó la definitiva superioridad marítima de Chile. En adelante podía contar con ella para respaldar el desembarco y el avance por tierra de las tropas chilenas. En efecto, una vez abierto el frente del Pacffico, el desembarco en Pisagua (28 de octubre), pemitió la toma de Iquique y Tarapacá. $Y$ es aquí, justamente, donde empieza la descomposición política del Perú.

\section{La crisis del Estado oligárquico:}

\section{¿guerra nacional o guerra social?}

Desde 1840 la economía peruana había reposado casi íntegramente en la explotación y exportación del guano de sus islas, un fertilizante utilizado mayormente en el abono de los campos ingleses. Pero el guano no sólo permitió el restablecimiento de la economía peruana luego de varias décadas de estancamiento, sino que posibilitó también el restablecimiento económico y político de comerciantes y terratenientes nativos ${ }^{7}$. Pese a sus fricciones internas, estos constituyeron la espina dorsal de la clase dirigente nativa. Su creciente poder económico fue nutrido sucesivamente por dud osas especulaciones financieras, por su participación en el comercio del guano, por su intervención en el naciente capital financiero y por los beneficios derivados de una excelente coyuntura agrícola. La traducción política de esta fuerza fue justamente la constitución del Partido Civil y el ascenso de su líder Manuel Pardo a la jefatura del Estado peruano en 1872. Después de cinco décadas terminaba así, al menos por el momento, el control politico que errática y sucesivamente fue ejercido

\footnotetext{
6 J. Valerie Fifer, Bolivia, Land Location and Politcs since 1825, Cambridge 1972, pp. 59.60.

7 Cf. Heraclio Bonilla, Guano y burguesía en el Perú. Lima, IEP, 1974.
} 
por innumerables caudillos militares. Otro eminente miembro de este grupo, e1 Coronel Mariano Ignacio Prado, era el presidente peruano cuando estalla el conflicto del Pacífico.

¿Cuál era la solidez de este Estado oligárquico y hasta qué punto la clase dirigente nativa había logrado una efectiva cohesión nacional? ¿La amenaza externa acabaría por cerrar las brechas existentes entre las diferentes clases de la sociedad peruana, entre las rústicas oligarquías provincianas y la educada élite limeña, entre, en fin, los diferentes estamentos étnicos de un país tan profund amente heterogéneo como el Perú? o, más bien, ¿agravarfa su disloque interno al quebrar sus débiles lazos de cohesión para hacer de esta dispersión uno de los factores esenciales de la victoria chilena? La simple narración de los acontecimientos encierra en sí una respuesta posible a estas cuestiones. Quisiera empezar citando el testimonio de uno de los testigos contemporáneos. Spencer St. John, el jefe de la Legación Británica en Lima, el 29 de octubre de 1879, escribió al Marqués de Salisbury, su Ministro de Relaciones Exteriores, lo siguiente:

"Tengo el honor de informar a Su Excelencia que con la llegada de las noticias del 9 del presente, que anunciaban la captura del "Huáscar" por los chilenos, surgió una crisis ministerial. El General Mendiburu y el resto del gabinete renunciaron y el Presidente mandó por el General La Cotera para que éste lo ayudara a formar un nuevo gabinete.

Hasta ahora nada ha sido hecho al respecto a pesar de que los puestos de Relaciones Exteriores y de Justicia han estado ocupados por pocos dias. $\mathrm{La}$ incapacidad de ambos representantes fue demasiado obvia como para que pudieran permanecer largo tiempo en el poder.

En estos momentos parece que no hubiera gobierno en absoluto. El Vice-Presidente está entermo $y$ en cama y no asume ningún trabajo, mientras que el General La Cotera, quien no es considerado capaz, es el único ministro nombrado.

Todo parece estar en un estado caótico: no hay un General al frente del ejército, nada se ha hecho para reforzar la defensa de la ciudad, a pesar de que en general se piensa que Chile prepara una expedición para atacar la capital. De todos lados la incapacidad parece dominar cada fracción importante, se informó que en el Sur los jefes del ejército se dedican a la diversión, como si la guerra no existiera (...)

EI Perú parece estar atacado por la parálisis; el mismo pueblo parece tan indiferente al futuro como la clase dirigente, que piensa más en sus ambiciones personales que en el bienestar del país".

Dos meses más tarde, en diciembre de 1879 , el mismo St. John informó lo siguiente:

8 Spencer St. John to the Marquis of Salisbury. Lima, October 29th, 1879. Public Record Office, Londres, F.O. 61/319. 
"En mi informe no 176 del 10 del presente, me referí a la creciente confianza como consecuencia del regreso del General Prado. En general se pensaba que reforzaría el gobierno y al rodearse de hombres capaces daría confianza al país. Ninguna de estas esperanzas se ha cumplido. Incapaz de obtener la cooperación de los líderes políticos, conservó al General La Puerta, un Ministro incompetente. Cada sección del gobierno parecía paralizada. Cuando el jueves 18 del presente el General Prado abandonó en un barco inglés el paŕs para dirigirse a los Estados Unidos, el pueblo se quedó sorprendido. Luego de su partida fue publicada una proclama diciendo que había partido con el fin de conseguir los medios necesarios para asegurar la victoria final: sus amigos escasamente respaldan esta declaración. En general se piensa que su partida no fue sino una desgraciada fuga. Siempre pensé que el General Prado no merecía el cargo que ocupaba. En cada gran ocasión hacfa alarde de su coraje, y es significativo que el hombre que fuera calificado como héroe del "dos de Mayo", ahora generalmente sea visto como un deplorable cobarde. E1 "dos de Mayo" es la fecha de la expulsión de la flota española en el Callao en 1866.

La reputación financiera del General Prado va a la par con su coraje: es acusado por todos los partidos de ser autor del más terrible sistema de expoliación. Se piensa generalmente que algunos jefes ambiciosos, ansiosos de conquistar el poder supremo hicieron ver alGeneral Prado que existía un complot para asesinarlo, y en vista de que su mente estaba debilitada por la enfermedad y la ansiedad, no pudo resistir estas presiones, huyendo de lo que probablemente no fue sino un peligro imaginario"9

El curioso comportamiento del Presidente Prado que describe St. John ilustra en su grado extremo la actitud asumida por el conjunto de la oligarqufa civilista durante el conflicto. En el inicio mismo de la guerra, en efecto, ante la demanda de un empréstito nacional por diez millones de soles, el gobiemo pudo obtener sólo 1'052,715.37 soles, suma básicamente aportada por las clases populares ante la resistencia de los opulentos capitalistas limeños ${ }^{10}$, y también como consecuencia de la escasez de liquidez monetaria ${ }^{11}$. Pero la partida del Presidente Prado, fue apenas el preludio de una crisis política mucho mayor.

El vacío de poder que se produce como consecuencia de la evasión de Prado posibilitó el establecimiento de la dictadura de Nicolás de Piérola. Lo fundamental de sus actividades, además de proclamarse "protector de la raza indígena" 12 , estuvo orientado a la organización de la defensa de Lima. Sin

9 Spencer St. John to the Marquis of Salisbury. Lima, December 22nd, 1879. F.O. $61 / 319$.

10. Jorge Basadre, Historia de la República del Perú. Lima 1961, 5a. ed., vol. IV, pp. 2380.2381 .

11. Cf. Robert G. Greenhill and Rory M. Miller, "The Peruvian Government and the Nitrate Trade, 1873-1879". en Journal of Latin American Studies. Londres, 5, 1, pp. 107-131. Jorge Basadre, op.cit., vol. V, p. 2444. 
embargo, y pese a sus esfuerzos, las derrotas de San Juan y Miraflores (enero de 1881) determinaron el colapso de su gobierno, y la ocupacion chilena de Lima. Es de interés comprobar que durante el breve gobierno de Piérola las grietas y el conflicto social interno se hicieron mucho más profundos. Ni la invasión chilena, ni el colapso económico y militar del Perú hicieron que la oligarquía civilista olvidara su odio social contra Piérola, el aristócrata arequipeño, quien como Ministro de Balta en 1868 le había arrebatado el estupendo negocio del guano para confiarlo al comerciante francés Auguste Dreyfus. "Primero los chilenos que Piérola", fue el pronunciamiento de la oligarquía civilista ${ }^{13}$, subordinando de esta manera su precaria conciencia nacional a los imperativos de su conciencia de clase. La guerra nacional entre el Perú y Chile ahora daba paso y acompañaba a una pugna interna mucho más significativa, a aquella que oponía las diferentes clases y clientelas políticas de una socied ad profund amente dividida.

Con la ocupación de Lima y la destrucción del Estado oligárquico se produjo inmediatamente una fragmentación del poder Gobiernos que se sucedian vertiginosamente o que mutuamente competían por imponer su autoridad respectiva. Esta guerra interna, en última instancia, no hacia sino traducir los intereses irreconciliables de los diferentes caciques y caudillos y de sus diferentes clientelas políticas. Como ninguno de ellos tuvo una base autónoma de poder lo suficientemente sólida, el resultado fue una profunda inestabilidad. El mantenimiento o la ampliación de su esfera de poder en este contexto, dependia sólo del apoyo y de la caución del ejército chileno de ocupación. Los sucesivos gobiemos de Francisco García Calderón (22 de enero de 1881), de Lizardo Montero (6 de diciembre de 1881), de Miguel Iglesias (30 de diciembre de 1882), trad ujeron esta inestabilidad, ante la perplejidad de los chilenos quienes no sabian con quien discutir las condiciones de paz. Pero lo que esta fragmentación e inestabilidad política encerraban era tambiên la oposición profunda entre intereses contradictorios. La desaparición del Estado oligárquico como consecuencia de la guerra revelaba toda la precariedad de la sociedad peruana y la profunda vulnerabilidad de la cohesión obtenida por la dominación oligárquica. Estas diversas clientelas politicas empezaron a disputarse ard ientemente los restos de poder, no sólo en las diferentes Asambleas provinciales, sino también de manera mucho măs desnud $\mathrm{a}$, a traves de enfrentamientos armados. No fue otro el significado de la convocación casi simultánea de cuatro diferentes asambleas legislativas: la de Chorrillos, por García Calderón (junio de 1881); la de Ayacucho, por Piérola (julio de 1881); la de Cajamarca, por Iglesias (diciembre de 1882); y, la de Arequipa, por Montero (abriljulio de 1883) ${ }^{14}$

13 Jorge Basadre, Perú problema y posibilidad. Lima 1931, p. 139.

14 Jorge Basadre, op.cit. vol. VI, , 2613. 
Pero la elocuencia de las armas se impuso ahi donde el verbo era impotente. El combate de las tropas de Cáceres contra las de Garcia Calderỏn en San Mateo y Chicla en julio de $1881^{15}$, contra las de Panizo en Acuchimay el 22 de febrero de $1882^{16}$, contra las de Iglesias desde el "pronunciamiento" de Montán, o los sangrientos enfrentamientos entre Puga e Iglesias, fueron el resultado y los indicios de esta fragmentación y oposición internas entre los diferentes grupos de la sociedad peruana. La guerra nacional contra Chile habia virtualmente terminado en enero de 1881 con la ocupación de Lima, no obstante la admirable resistencia de Cáceres y de sus "montoneras". De las cenizas humeantes de la guerra emergía ahora el conflicto de una sociedad consigo misma. $Y$ era esto lo que tal vez importaba más en la conciencia de sus hombres.

Pero la destrucción del Estado oligárquico no sôlo configura, como se acaba de ver, una suerte de conflicto "horizontal" entre las diferentes fracciones de la clase dirigente. Ella también da paso a una oposición mucho más importante: entre la clase dirigente y el conjunto de las clases oprimidas. $Y$ es este conflicto el que subyace en lo que fue la preocupación central de todos los gobiernos desde García Calderón hasta Iglesias: el problema de la paz con Chile.

Después de la caída de Lima, en efecto, los diferentes gobiemos que se instalaron con el apoyo del ejército chileno concordaron en que era necesario establecer la paz con Chile al más breve plazo. Sus diferencias giraban en torno a las condiciones, más no sobre el principio. Frente a esta renuncia del conjunto de la clase dirigente, sólo Andrés A Cáceres y sus "montoneras", emprendio desde 1882 en las serranías andinas una obstinada resistencia a la vez contra la ocupación chilena y contra la actitud de la oligarquía civilista. Como dirá más tarde el mismo Cáceres:

"Chile dedicó toda su actividad a la consecución de tal propósito, valiéndose de los medios más viles e inescrupulosos. $Y$ para mayor desdicha encontró compatricios nuestros que, inspiråndose más en sus personales ambiciones que en las supremas conveniencias de la patria, tornäronse en eficaces colaborad ores del invasor.

Si nos cupo tan mala suerte, no se debió en modo alguno a la presión de las armas enemigas, sino que es imputable más bien al estado de desorganización en que se encontraba el Perú, a los desaciertos de sus dirigentes y a la menguada actitud de elementos pudientes que no supieron ni quisieron mantener firme hasta el último extremo la voluntad de luchar por la integridad territorial de la nación; y que, lejos de estos, coadyuvaron a la labor emprendida con inaudito refinamiento por el enemigo, dejando al ejército patrio no sólo sin apoyo alguno, sino restảndole el que podían haberle proporcionado.

En el Sur, el ejército de Arequipa, fuerte de más de 4,000 hombres, y sin

16 Ibid: , p. 2584 
haber prestado ningún servicio a la patria, se dispersó sin combate. En el Norte, se proclamó la paz a todo trance aceptándose las cláusulas de paz del invasor. En la capital de la República, gente acomodada que al comienzo deseaba la guerra, abominaba la resistencia armada y sólo pensaba en poner a salvo sus personas y sus bienes con el advenimiento de la paz". 17

¿Pero, cuáles fueron los intereses sociales comprometidos en la Jemanda de una paz inmediata? Su exigencia respond ía, sin duda, al reconocimiento de la debilidad militar del Perú y a la inutilidad de continuar con la guerra en tales condiciones. Pero también se debió a consideraciones mucho más urgentes. Con las sucesivas victorias del ejército chileno, no sólo se quebraron los tenues lazos de cohesión a nivel nacional, sino que esta desorganización fue probablemente mucho más intensa dentro de cada región. Terratenientes y comerciantes, es decir, el conjunto del caciquismo local, de repente se encontró en la más absoluta impotencia para mantener el control de sus subordinados. También aquí al saltar irremediablemente los lazos de sujección social y política se produjo lo inevitable: el saqueo, el pillaje, la destrucción de personas y propiedades. Nada mejor que el testimonio de un terrateniente para revelar el significado de estos acontecimientos:

"Todo Chiclayo ha sido vergonzoso no por los chilenos, sino pásmense, por los robos de los mismos hijos de Chiclayo, la plebe más imbécil y degrad ada. No sólo formaban cola tras de los chilenos cuando incendiab an y sacaban muebles y artfculos del país como arroz, marz, y luego los del pueblo chiclayano barrían y recogían con todo, sino que se han ocupado en denunciar, ellos mismos: al Sr. Lynch y a los jefes, quienes eran los hijos del país que tenían fortuna; en fin todos los trapos sucios de la casa los mostraron"18

A un oligarca limeño o a un altivo terrateniente serrano no le fue muy difícil decidirse entre Chile o el despojo de sus propiedades por turbas exaltad as que no sólo hab ran sido secularmente sus explotados, sino que para el colmo, ¡eran negros, chinos e indios! Es este profundo miedo social el que explica la ansiedad del Alcalde de Lima por la pronta ocupación de la ciudad por el ejército chileno ${ }^{19}$ así como el deseo de la clase propietaria de que continuase la ocupación. Spencer St. John, el alerto Ministro inglés, dirá por esto:

"En efecto, el miedo al regreso de Piérola y su gobierno, apoyado por las clases bajas, las que sólo la otra noche cometieron tales excesos, hace

17 Andrés A. Cáceres, La guerra del 79: sus campañas. Lima 1973, p. 250.

18 Carta de Antero a Ramón Aspillaga Hda. Cay alti, 18 de octubre 1880, Archivo del Fuero Agrario. Lima, vol. 20.

19 Henri Favre, "Remarques sur la lutte des classes au Pèrou pendant la guerre du Pacifique", en Litterature et société au Pérou du XIXé siécle a nos jours. Grenoble. Cerpa 1975, pp. 58-59. 
desear a aquellos que posean propiedades que los chilenos prolonguen la ocupación del país hasta que vuelva la tranquilidad" 20

Del mismo modo, García Calderón, quien organizara en Magdalena el gobierno que sucede a Piérola, luego de acusarlo de sembrar "la anarquía en las clases sociales" 21 expresará en su "Proclama" al pueblo el 26 de febrero de 1881 :

"Con la guerra han sufrido aquellos que tenian fortuna, mucho más que aquellos que no vivían sino de su trabajo. . . Las desvastaciones causadas por el enemigo han generado la pérdida de centenas de haciendas y casas que representaban millones de soles. Si estas haciendas no se cultivan, si estas casas no se reconstruyen, el honesto trabajador que vive de sus brazos, no encontrará a nadie para darle su subsistencia. Los males que sufre nuestra patria desde hace dos años, no terminarán sino con el trabajo, y no habrá trabajo tanto que no habrá paz. Acaso aquellos que se llaman ticos, si existen todavia, son responsables mientras son saqueadas sus haciendas y sus casas? Ciertamente no. La causa de nuestros males es la guerra, guerra que por desgracia nuestra no podemos continuar" 22

En esta misma "Proclama" García Calderón pasará más adelante de la justificación de la paz a una clara advertencia a los "trabajad ores honestos":

"Uds. serán víctimas del desempleo si los hombres a quienes llaman ricos, pierden su fortuna; estos hombres tienen los mismos intereses que Uds., y sin ellos Uds. sufrirán. Sólo aprovecharán el desorden los individuos perversos que siembran el grano funesto de la discordia" 23

Fácil es imaginarse, dentro de este contexto, el profundo alivio que significó para la clase dirigente peruana la enérgica demanda de paz lanzada desde "Montán" por el Coronel Miguel Iglesias. Un alivio traducido en el apoyo militar a Iglesias, en el desconocimiento a las autoridades nombradas por Cáceres, la heroica figura de la resistencia, y en el subsidio al ejército chileno de ocupación. Nada quedaba ya ni de sus ensueños nacionales ni de su promesa de 1821. La decidida adhesión al ejército del general chileno Martiniano Urriola, en el mismo momento en que combatía contra éste el pueblo de Huanta al mando de Miguel Lazón, probablemente constituya el más trágico epitafio de la historia política de la clase dirigente peruana ${ }^{24}$.

Mr. St. John to Earl Granville. Lima, Jan 22nd. 1881. F.O. 61/333.

21 "Mensaje del presidente Provisorio de República don Fco García Calderón al Congreso de Chorrillos, el 10 de julio de 1881", en Pedro Ugarteche y Evaristo San Cristóbal, Mensajes de los Presidentes del Perú. Lima 1945, vol. II pp. 116-117.

23 Ibid.

24 Jorge Basadre,op.cit., vol. VI, pp. 2637-2638. 
Pero el urgente reclamo de paz, la renuncia a la resistencia, el miedo y desprecio a las clases populares fueron los rasgos del comportamiento no sólo de la clase dirigente limeña, sino también de las diferentes oligarquias regionales. En la costa norte, por ejemplo, Antero Aspillaga escribe en una carta lo siguiente:

"Ahí tienen los intransigentes con la paz el resultado de su inicua y antipatriótica propaganda. Es inicua porque la pregonan sin desearla ni poderla hacer; $y$ antipatriótica porque cavan más el abismo en el cual nos hundimos todos los peruanos desde los memorables desastres de San Juan y Miraflores. Por supuesto los que nada tienen no pierden nada. Y por desgracia de estos hombres inconscientes se componen los grupos que gritan la guerra imposible, siguiendo a Piérola y a sus partidarios. Será difícil encontrar un país que haya tenido suerte más negra que nuestra desgraciada patria, y en ningún país habrán contribuido más sus propios hijos a escarnecerla y destrozarla como en el Perú. En fin si la política interior cambia y todos se desengañan que sólo en el Gobierno Provisorio está nuestra salvación, este malestar cambiará y cesará la recia tempestad que nos destroza" 25

Un recuento periodístico de la expedición del ejército chileno sobre esta región sefiala al respecto:

"Durante el día (24 de setiembre de 1880), el Prefecto recibió una nota del jefe de la expedición, señor Lynch, en la que se exigía la entrega pacífica de la plaza, imponiéndole a la vez un cupo de no sé cuantos miles de soles de plata. La respuesta del Prefecto nos es desconocida, pero se nos asegura que ella estaba concebida en términos convenientes y patrióticos y que comprometían de manera seria su patriotismo. Sin embargo, a pesar de esto, dicho funcionario determinó abandonar la estación de Monsefú y a las 10 p.m. se dirigió con toda su gente a Chiclayo, de cuyo lugar salió en tren especial a la hacienda de Pátapo para dirigirse de allí a Chongoyape. Esta población se quedó, pues, completamente sola, abandonada de las autoridades y resguardad a únicamente por la guardia urbana compuesta de extranjeros; pues hasta el Alcalde Municipal y la mayoría de sus colegas habian abandonado la ciud ad" 26

Esta misma actitud describe Lynch, el jefe de la expedición chilena, en una carta a Adolfo Salmón, Prefecto de La Libertad:

"Tengo el placer de decirte que en mis incursiones tú eres el único jefe que ha comprendido su deber. He visto con pena en todas partes que lugares merecedores de mejor tratamiento están gobernados por individuos cobardes que nada saben de las modernas leyes de la guerra. Ningún Prefecto ni Gobernador se ha quedado en su puesto, a pesar de mi pedido urgente de que así lo hicieran. Todos han huído a las montañas, atemorizando a la gente que vive en los lugares por donde pasan, aprovechando la situación para quitarles algo. En Paita pude detener al

25 Carta de Antero a Ramón Aspill aga, Hacienda Cayaltí, 9 de mayo de 1881, Archivo del Fuero Agrario, Lima, vol 24.

26 El Nacional, Chiclayo, octubre 24 de 1880, National Archives, W ashington, Microfilm Publications, T. 393.3. 
comandante Pardo de Zela y lo dejé tranquilamente en su puesto (..) No sé, mi amigo, que me asombra más, si la riqueza increible de esta parte del Perú o la inarrable indolencia de sus habitantes. Yo envidio para mi país la belleza y fertilidad de los valles despreciados por tus compatriotas. Hay mucho que hacer en el Perú para que la belleza que la naturaleza le ha concedido no se pierda. Estoy sorprendido de la ignorancia de las clases bajas, que parecen no saben sus deberes para con ellos y su nación. Trabaja amigo mío por tu rico e infortunado país y haz uso de la penosa misión que te ha dado esta guerra, que estoy seguro que tu nación se levantará de nuevo próspera y feliz" 27

Es cierto que el gobierno peruano amenazó con penas severas a quienes aceptasen las demandas del ejército de ocupación, como también destituyó y enjuició al Prefecto de Lambayeque, José Manuel Aguirre, y al de La Libertad, Adolfo Salmón. Pero, y esta la cuestión capital, ¿podía efectivamente un casi inexistente "gobierno nacional" doblegar la resistencia de una clase conciente de sus intereses y temerosa de perder las bases de su fortuna?

Finalmente, ¿cuál fue el costo material de estas curiosas alianzas clientelísticas y de estas "desalianzas" nacionales? Debe recordarse que los dos objetivos centrales perseguidos por el ejército chileno eran, de una parte, la apropiación de los yacimientos de guano y de salitre, y por otra, la destrucción de los recursos económicos más significativos para evitar que el Penú pudiera continuar la guerra o resistir la ocupación. Lo primero fue obtenido prácticamente al comienzo mismo de la guerra, mientras que la expedición de Lynch al norte peruano (el área de las importantes plantaciones algodoneras y azucareras) obedecía precisamente a la necesidad de debilitar económicamente al Perú, tanto a través del control directo de estas unidades productivas, como de la imposición de onerosos "cupos" de guerra. La clase terrateniente del norte, frente al avance de Lynch, no sólo se limitó a buscar la protección del ejército chileno ante el desbande y el ataque generalizado de sus esclavos chinos, sino que recurrió a la transferencia real o ficticia de sus haciendas a ciudadanos extranjeros, a fin de que, ahora como propiedad de neutrales, estuviesen al abrigo de la destrucción y de las imposiciones de guerra. Algunos ejemplos permiten ilustrar esta situáción.

Cuando el ejército chileno ocupa la hacienda "Cayaltî" el 7 de Octubre de 1880 y amenaza arrasarla es Antero Aspíllaga, a nombre de Prevost y Co, quien formula una firme protesta, aduciendo el carácter neutral de la propiedad. Sin embargo, como explica el mismo Antero en una carta privada a su hermano Ramón:

27 Patricio Lynch a Adolfo Salmón, San Pedro, 14 de octubre de 1880. National Archives. Washington. Microfilm Publications T 393,3. 
La determinación de transferir en la forma de arrendamiento Cayaltí y sus capitales a Prevost y Co., hacía de este fundo propiedad americana, lo que nos ha salvado y nos salvará en el futuro de mayores prejuicios. Es lo mismo que hace meses pedimos que se hiciera y que por los consejos del abogado se demoró hasta vemos cerca de la última extremidad" 28

Pareciera que transacciones similares ocurrieron en las barriadas "Leche":29, "Chiclín"30, "Galind o" 31 en La Libertad; "Puente" y "Palo Seco" en Chimbote; y, "San Jose" en Nepeña 32 .

Evidentemente que esta cadena de transferencias contrariaba los planes de Patricio Lynch. El mismo, o sus oficiales, tuvieron ahora que dictaminar qué haciendas pertenecían efectivamente a extranjeros y cuáles habían sido objeto de transacciones muy recientes o simplemente representaban cesiones ficticias. Esta tarea de depuración documental, que sin duda alguna despertaría la envidia de cualquier historiad or contemporâneo, no estaba, sin embargo, exenta de serias complicaciones. En efecto, gran parte de estas haciendas pertenecían formalmente a peruanos, pero al mismo tiempo estaban gravadas por importantes hipotecas como consecuencia de la imprevisión y del derroche de sus propietarios ${ }^{33}$. El control de las operaciones, y sobre tado de los beneficios, era por consiguiente ejercido por bancos y casas comerciales inglesas, francesas o norte americanas. En cualquier caso fue a través de este mecanismo que empezó la desnacionalización de la propiedad agraria en la costa norte y la fusión de muchas anidades agrícolas, proceso que se intensifica y que culmina poco después del término de la guerra con Chile.

Cambios similares en la propiedad de la tierra ocurrieron también en la serranía andina. En la región de Huancavelica, por ejemplo, el desarrollo agrario hasta 1883 estuvo caracterizado por una permanente fragmentación de los grandes latifundios. Este proceso, totalmente opuesto a lo que ocurría en la mayor parte de las áreas nurales del Perú, fue consecuencia de las peculiares

28 Carta de Antero a Ramón Aspillaga Hda. Cayolt1, 18 de octubre 1980, Archivo del Fuero Agrario. Lima, vol. 20.

29 S.C. Montjoy to William Hunter, Segundo Asistente del Secretario de Estado, Lambayeque, Jan. 25th., Mocrofilm Publications T 393,3.

30 Ibid., Lambayeque, Jan 25th, National Archives. Washington. Microfilm Publications, T 393,3 .

31 Ibid., Lambayeque May 6th 1881, National Archives, Washington Microfilm Publịcations T, 393,3.

32 Spencer St. John to Patricio Lynch. Lima, Sept. 11th 1880, National Archives. Washington. Microfilm Publications T 393,3.

33 Alejandro Garland, La industria azucarera en el Perú (1550 1895). Lima 1895; y, Douglas E, Horton, "Haciendas and Cooperatives: A Preliminary Study of Latifundist Agriculture and Agrarian Reform in Northern Peru", en Land Tenure Center. Wisconsin 1973. 
condiciones económicas y sociales de Huancavelica durante la Colonia Ahora bien, la consolidación de la mediana propiedad fue detenida y su proceso invertido al plegarse estos pequeños hacendados al ejército chileno en busca de protección, también esta vez, frente a la amenaza de las montoneras campesinas de Cáceres o del levantamiento de sus siervos indios. Este hecho, al igual que en el norte, abrió el camino a una drástica concentración de la tierra en los años inmediatamente posteriores a la guerra con Chile ${ }^{34}$.

Conciencia étnica y conciencia de clase en el contexto de una guerra nacional

Carey Brenton era un lugarteniente inglés adscrito a la jefatura de campo del ejército peruano durante la defensa de Lima en enero de 1881. En un informe elevado a su Comandante William Dyke, Carey Brenton describe detalladamente la composición y las características del ejército peruano encargado de la defensa de Lima, de su armamento, su vestimenta, a la vez que deja constancia de su admiración por el trabajo desplegado por las "rabonas", es decir, las humildes mujeres que inseparablemente estuvieron al lado de los soldados peruanos a lo largo de todas estas contiendas. Sobre la composición de este ejército escribe lo siguiente:

"La mayoría de los oficiales, sobre todo los superiores, son descendientes de los viejos colonizadores espanoles, y tienen, por ello, poco en común con sus hombres. El espíritu de cuerpo es desconocido, y si bien, el sold ado peruano grita invariablemente ¡Viva el Perú! antes de cada ataque o huyendo de su enemigo, éste no conoce su significado, simplemente repite lo que se le ordena. Muchos de ellos eran totalmente ignorantes de la causa por la cual peleaban, imaginando que se trataba de una revolución cuyas partes contrincantes eran liderad as respectivamente por el General Chili y por Piérola. También fui informado por un oficial de que muchos soldados habían dicho que: "ellos no se dejarían matar por la causa de los hombres blancos" 35 .

Los acontecimientos ocurridos durante la sombria noche del 16 de enero, luego de la derrota de Miraflores y en la víspera del ingreso de las tropas chilenas a Lima, fueron igualmente detallad os por el Ministro inglés Spencer St. John. En una parte de su extenso informe escribió:

34 Henrỉ Favre, "Evolución y situación de las haciendas en la región de Huancavelica", en La hacienda en el Perú. Lima. Instituto de Estudios Peruanos 1967, pp. 240.242.

35 "Report of Proceedings of Lieut Carey Brenton Whilst attached tothe Headquarters Staff of the Peruvian Army, engaged in the Defence of Lima against the Chilians". F.O. $61 / 337$ fol, 156 
st .. sin embargo, tan pronto como oscurecio se oyeron disparos en todas las direcciones de la ciudad, hubo incendios, uno muy grande en la plaza del mercado y en las calles circund antes. La masa cobarde estaba atacando $\mathrm{y}$ asesinando a los tenderos chinos, quienes no estando preparados para este ataque fueron aniquilados con suma facilid ad; se supone que murier on de 70 a 80 . La masa estuvo liderada por oficiales peruanos en uniforme, a quienes los chinos conocían. Fue una noche de ansiedad, en vista de que nadie sabia cuántos quedaban en Lima del ejército vencido de 30,000 hombres; el fuego fue por momentos muy seguido. La escena en la Legación inglesa era tríste. Por 10 menos 700 mujeres y niños de las mejores familias limeñas llenaban todos los cuartos; todos ellos no sólo temiendo la noticia de la muerte de un pariente en las batallas recientes, sino también de que en cualquier momen to la plebe nos atacaria. Fue una noche de cansancio para todos, aunque la presencia del Admiral y sus adjuntos con cinco "casacas azules", permitra cierta tranquilidad" 36 .

Los acontecimientos relatados por los dos observadores ingleses consti tuyen una buena introducción a un problema cuya discusión constituye la segunda parte de este documento. Este problema es el de la fractura y el conflicto étnico al interior de una guerra nacional. En la primera parte se vio cómo la destrucción del Estado oligárquico, como consecuencia de la invasión chilena y de la ocupación, provocó el enfrentamiento directo entre, de una parte, la clase dirigente contra el conjunto de las clases subordinad as y, por otra, entre las diferentes fracciones de esta clase y entre, también, las diferentes clientelas políticas liderad as por los múltiples caciques y caudillos locales. Pero el conflicto armado contra Chile generó también, como se pasará a mostrar en las págỉnas siguientes, otro tipo de enfrentamiento y que, en cierto modo, atravesaba las líneas de clase para oponer, entre si, al conjunto de los estamentos que integraban la sociedad peruana.

Bien conocido es el hecho que el Peru es un país étnicamente heterogéneo. Ahŕ reside justamente uno de los legados contemporáneos de la colonización hispánica. La división-oposición entre blancos, indios y negros fue una consecuencia y una de las condiciones del mantenimiento de la dominación colonial. Esta fractura no sólo que no fue resuelta cuando se establece el Estado nacional, sino que la oligaquia civilista, básicamente limeña y blanca, tuvo la prudencia y el suficiente tino de no plantear siquiera su discusión. La cruel derrota que sufrieron las masas indias con el aplastamiento de la rebelión de Túpac Amaru, su debilidad y su dispersión posterior, facilitaron seguramente su control social y político por parte de los poderosos caciques locales. En el caso de los negros, por otra parte, su debilidad numérica, el escape a su condición 
opresiva que le brind aba el "cimarronaje", asociado a una dispersion semejante a la de los indios, eran condiciones que igualmente restaban tod a peligrosidad a la presencia del grupo negro frente a la dominación de los blancos. Este mosaico racial se complica aún más cuando la oligarquia criolla se ve obligad a a importar masivamente cerca de 92,130 chinos entre 1849 y 1874 , como respuesta a la crisis interna de la mano de obra y a la movilización de la economía peruana producida por la explotación del guano, de los ferrocarriles, del algodón y de la caña de azúcar ${ }^{37}$ Pero también aquí, la dispersión del grupo chino en estas diferentes unidades productivas atenuaba grandemente la peligrosidad de sus revueltas en contra de la explotación de que eran víctimas. Estas rebeliones no fueron nunca más allá de un estricto marco local ${ }^{38}$. Con la destrucción del Estado oligárquico, la dispersión del ejército y la desorganización de la sociedad peruana, el encuadramiento de esta sociedad entre 1879 y 1884 presentaba ahora características totalmente diferentes a las que ofrecía en las décadas anteriores. Examinemos el impacto de esta desorganización en el desencadenamiento y en el carácter de la movilización de estos diferentes segmentos étnicos.

Los chinos desde el arribo del ejército de Lynch a las plantaciones del norte, se plegaron rápidamente a sus filas, participando activamente en el saqueo de las propiedades de sus antiguos amos y revelando los lugares dónde habian sido ocultadas las maquinarias e instrumentos de la hacienda. Este comportamiento, obviamente no traduce ni lealtad, ni adhesión a Chile, o a su ejército. Tampoco puede hablarse de un "patriotismo chileno" de los chinos, ni de una "traición" hacia el Perú. Sería exagerado suponer que un "collie" chino de la época era capaz de distinguir un chileno de un peruano, Los chinos, simplemente, fueron sometidos a una atroz explotación por parte de los terratenientes nacionales, y la inserción de ellos dentro de las filas del ejército chileno fue la manera más lógica de traducir y expresar el contenido odio social contra sus antiguos explotadores. ¿Fenómeno único? De ninguna manera. Después de todo, el audaz Pizarro pudo derribar con su puñado de hombres el impresionante Imperio de los Incas porque supo aprovechar y captar la adhesión y la complicidad de las etnías mal sometidas por el estad o Inca. El problema para los chinos, por lo menos, es que su adhesión al ejército chileno no modifico en

37 Wilma E. Derpich, Introducción al Estudio del trabajador coolie chino en el Perú del siglo XIX, tesis inédita. Universidad Nacional Mayor de San Marcos, Lima 1976, pp. 158.162 .

38 Watt Stewart, Chinese Bondage in Peru. A History of the Chinese in Peru, 18491874. Duke University Press 1951 . 
nada su situación material y social. Parte de ellos fueron remitidos por Lynch para trabajar en las salitreras y depósitos de guano en el sur ${ }^{39}$. Otros dos mil chinos por órdenes del Ministro de Guerra Vergara y pese a la oposición de Lynch $y$ otros oficiales chilenos, fueron incorporados al ejército chileno $y$ encargados del entierro de los muertos y cuidado de los heridos ${ }^{40}$. Durante la ocupación de Lima, finalmente, el Ministro inglés Spencer St. John constató que:

"... el día 31 de marzo ellos estuvieron expuestos al mismo mal trato por parte de los chilenos. Con el pretexto de que unos ladrones habfan ido a refugiarse al teatro chino, los soldad os chilenos abrieron violentamente las puertas del teatro y empezaron a maltratar y a apresar a los presentes. Algunos chinos, se dice, comenzaron a disparar contra ellos, hiriendo a dos. Ante esto, los oficiales chilenos enviaron por refuerzos, capturando a 500 hombres $v$ saqueando a todas las casas y tiend as de los chinos en ese vecindario" 41 .

Cuando Lynch llega a Guadalupe, en la provincia de Pacasmayo, se plegaron a su ejército entre 600 y 800 chinos, quienes se dedicaron al saqueo de haciendas y casas particulares 42 . Este saqueo continuó también en Casagrande, en el valle de Chicama. En la hacienda "Pátapo", en la provincia de Chiclayo, los peones chinos abandonados por sus amos denunciaron a Lynch el escondite de las locomotoras del ferrocarril local ${ }^{43}$. Después de observar el desbande de los chinos de las haciendas de la región y juzgar que "todo esto es pues de sacar del quicio al más tranquilo", Antero Aspallaga explica el por que de la relativa tranquilidad de los chinos de "Cayaltr":

"Cuando llegaron los enemigos a Uncupe, llamamos a todos los chinos de esta hacienda, les hicimos presente el peligro y las amenazas que teniamos, pero que confiábamos en su lealtad y en aprecio que hacían de nosotros. Con satisfacción les diremos que su respuesta nos llena de orgullo y de agradecimiento; todos dijeron que ninguno se separaría, que estaban contentos, que el patrón era bueno, mejor que en todas las haciendas y que no tuvieramos cuidado. Su conducta, en efecto, ha sido y es satisfactoria y debemos premiarla para que sea estímulo y confianza en el porvenir. Desde este pago les aumentamos cincuenta centavos a su quincena. En efecto, qué son diez chinos prófugos en tre 354 que tenemos bajo contrata? ${ }^{44}$.

S.C. Montjoy to William Hunter. Lambayhque, Nov, 3rd. 1880. National Archives. Washington. Microfilm Publications T 393/2.

40 Henri Favre, "Remarques....", op.cit., p. 68.

41 Spencer St. John to Earl Granville, Lima, May 3rd. 1881, F.O. 61/333.

42 Ibid,

43 El Nacional, octubre 24th. 1880, Microfilm publications, $T$ 393/2.

44 Carta de Antero a Ramón Aspíllaga. Hda. Cayaltí, 10 de Octubre de 1880, Archivo del Fuero Agrario, Lima, vol. 24, 
Cuando Lynch descendió hacia el sur, en diciembre de 1880 se plegaron a su ejército cerca de 1,000 peones chinos en el valle de Cañete ${ }^{45}$. En el sur como en el norte la adhesión de los chinos al "Príncipe Rojo" (el sobrenombre de Patricio Lynch) y su ejército traducía la revancha que ahora tomaban contra sus amos:

"Los libró el príncipe rojo a los chinos de Cerro Azul los libró el príncipe rojo se acabó la esclavitud, y marcharon en legiones tras el gran Patricio Lynch dejando las plantaciones los siguieron hasta el fin. A coltal cabeza diablo gritaba Liotang Sinchin a comel los liñones con palillos de malfil

Se cubrieron con mascarones y avanzaron pa'Lurín con banderas de dragones siguiendo a Liotang Sinchin y corriendo por las calles entraron a la ciudad mucho antes que lo hicieran las tropas del General Con furor vengaron los chinos a los chinos de Cerro Azul rompiend o así sus cadenas se acabó la esclavitud. Ellos fueron la avanzada para el gran Patricio Lynch y murieron cual valientes siguiendo a Liotang Sinchin" 46.

La evasión y el enrolamiento de los chinos agravaba aún más la ya deteriorada situación de muchos de los latifundistas norteños. Es significativo constatar, a este respecto, la preocupación de la clase dirigente y de muchos terratenientes por su situación material en medio de la profunda crisis que afectaba al país. No es otro el sentimiento que expresaba el Prefecto de La Libertad, Adolfo Salmón, en una carta dirigida al consul norteamericano Montjoy:

". . ya que los pueblos del norte han abdicado de su soberania y su dignidad saliendo al encuentro del invasor con la bolsa de rescate en lugar de recibirlos a balazos, aquí reivind icaremos a todo el norte, y no tema Ud. que arruinen Chicama, porque sin un quintal de azúcar, la chinada remitida bajo custodia al interior, las måquinas desarmadas y sus principales piezas en lugar seguro, apenas podrían quemar los cascos en el caso de que los dejara tranquilos día y noche la gente que bajo $m$ is órdenes tengo resuelta a defender su hogar En vez de esa tarea tendrán la más urgente de defenderse como puedan. Lo que sí me duele es que se lleven los chinos después de causar un gran desorden y cuando de nada pueden servirles, haciéndonos a nosotros tanta falta. Si usted pudiera, de un modo reservado, conseguir de Lynch que los vendiera de nuevo a los hacendados, yo se los pudiera comprar a peso de oro. Trabaje usted en ese sentido que tan to me interesa. .

45 Jorge Basadre, op cit , vol VI, p. 2506

46 'Los chinos de Cerro Azul", canción popular chilena, letra de Jorge Inostroza.

47 Adolfo Salmón a Santiago Montjoy: Malabrigo, octubre 15 de 1880 . National Archives. Washington Microfilm Publications T 393/3. 
En los desórdenes que acompañan la ocupación de Lima en enero de 1881, por otra parte, empiezan a surgir los signos inequívocos de la eclosión de un nuevo tipo de conflicto étnico. Esta vez no se trata del levantamiento del oprimido grupo chino contra el opresor grupo blanco; son indios y mestizos del ejército peruano que en medio del desbande y de la confusión de la guerra, procedieron al saqueo de las tiendas y a la matanza de sus propietarios chinos en Lima. Estas destrucciones, evaluadas en 364,777 libras esterlinas por el Comité de Comerciantes Chinos ${ }^{48}$, se produjeron también en Cañete, obligando a la colonia asiática de $\mathrm{P}$ isco a pedir la protección diplomática de Inglaterra ${ }^{49}$

Este dramático cuadro de descomposición y de conflicto étnico en el seno de las masas populares alcanza una mayor intensidad en febrero de 1881. Los chinos, una vez más, fueron también aquí las víctimas propiciatorias de los otros segmentos de la población oprimida. Esta vez los negros aprovecharon la desorganización para asaltar propiedades, matar propietarios blancos y peones chinos, pese a que este último grupo compartía con los negros la misma situación objetiva de dominación. Spencer St. John calcula entre 700 y 1,500 el número de chinos asesinad os por los negros durante esta revuel ta ${ }^{50}$. En esta guerra racial, a manera de compensación, seguramente se proyectaron hacia los otros grupos dominados las frustraciones y las humillaciones a que secularmente había sido sometida la población negra, esclava. La segmentación y opresión colonial no sólo que impedía la articulación de los intereses del conjunto de la población oprimida, sino que también ahora, como antes y como después, ocultaba al enemigo, desplazaba el conflicto y permitía la autodestrucción de las masas populares. Se requieren todavía los estudios necesarios sobre la estructura de las relaciones inter-étnicas en la sociedad peruana para explicar las razones profundas de este modelo de protesta. Incluso, el recurso de la psicología social para descifrar el significado del ritual de las matanzas. Por su valor como descripción de este problema, se reproduce aquí el extraordinario testimonio de Juan de Arona sobre el levantamiento negro en el valle de Cañe te:

"La acción más heroica y original de nuestra colonia china en esos aciagos días, y que se quedaría en el olvido si no la sacáramos ahora a la luz, fue el sitio improvisado que resistió por tres meses contra las fuerzas sublevadas del valle de Cañete. Los negros y cholos de ese lugar, llevaban 30 años de odio gratuito por esos infelices inmigrad os; y aprovechando de la acefalía 1st. 1881. F.O, 61/334.

49 La Colonia Asiática al Exmo. Sr. Envfado Ex traordinario y Ministro Plenipotenciario de su majestad Británica, Pisco, March 7th 1881. F.O. 177/168.

50 Spencer St. John to Ear] Granville. Lima, Mayo 3rd 1881. F. O. 61/333. 
en que quedaron los pueblos con la ocupación de Lima por los chilenos efectuad a el mes anterior, se levantaron en febrero de 1881 a matar chinos. El fútil pretexto inmediato fue una reyerta habia entre un chino y una negra, por haberla mojado ésta a aquel en el juego de carnaval El camaval fue de sangre, y el Miércoles de Ceniza, de cenizas sin cuento, porque los negros y cholos al mismo tiempo que mataban chinos, incendiaban los cañaverales de las haciendas escuetas, en las que ellos habian seguido viviendo manumisos y parásitos desde 1855 . La primera operación quedó terminada poco menos que en un dfa, la segund a fue larga: acabar con los vastos cañaverales de ocho haciendas, muchos de los cuales seguían creciendo después de quemad os, agotar por un robo lento y cotidiano sus inmensas existencias de azúcar, ron, ganados, elementos, destruir la obra de una civilización secular, y por manos de torpes has ta la desvastación, no era $\tan$ hecedero.

Así por semestres y años, Cañe te humeaba, y sus callejones eranrecorridos por cáfilas de merodead ores pacíficos que descendían de las quebradas y valles al olor del gran botín. Debran parecer las piaras de camellos del Asia Menor conduciendo los fragmentos del Coloso de Rodas cuando este antiguo monumento de la civilización se vino a tierra.

Las recuas de mulas o burros, las carretas desfilaban a la luz del sol cargad as de azúcar en panes o sacos, moscabada o blanca; de ron, de piezas de maquinaria, de muebles, de todas las riquezas del naufragio. Eso es 10 que el Perú debe a sus plebes! El ocupante de la capital ponía orejas de mercader a los clamores de los propietarios, que en todo el tiempo de la ocupación chilena, casi tres afios, no pudieron aportar por sus fundos. No convenía al enemigo desprender fuerzas del cuartel general en servicio y obsequio de los peruanos debelados.

La turba de negros y cholos armados, montados y sin pueblo que los contrarrestara, porque ellos solos habían sido siempre en realidad toda la población del valle, se precipitaron sobre las haciendas una por una. Los asiáticos sorprendidos, indefensos, ignorantes de su culpabilidad, eran muertos a palos, a machetazos, a pedradas, o cuchillo, de mil maneras, Algunos dependientes subalternos, únicos que por entonces tenían a su cargo los abandonados fundos, al ver llegar las hordas, creyendo cargarse de razón, encerraban a los perseguidos en sus grandes galpones; los asaltantes quemaban o echaban abajo las puertas y ejecutaban a discreción a los inocentes.

A los que buscaban su salud introduciéndose en los albañales más o menos largos, los esperaban en los registros de entrada y salida y conforme iban apareciendo les daban muerte. Otros infelices creyendo todavia en el tradicional sagrado, se asilaban en la Escuela Casagrande, en la que ya no se velaba la sobra de los ausentes años; allí también eran ultimados por los foragidos, ávidos de venganza y de rapiña, pues de paso se llevaban de encuentro muebles, vidrios, puertas, papeles, destruyendo todo y haciendo con los fragmentos autos de fe en hogueras que encendían en el centro mismo de las habitaciones de sus antiguos y al parecer queridos amos.

Los cadáveres de los chinos eran arrojados fuera, al medio del patrio sefforial, en donde antes que de pasto a las aves, servían de profanación báquica y canivalesca a las mujeres y a los muchachos. Las mismas negras que habran compartido el contubernio regalado de las víctimas, escarnecían sus cuerpos mutilándolos y poniéndolos por irrisión en la boca 
entreabierta, figurando un cigarro, los miembros sangrientos y palpitantes que les amputaban. "Déjame êse para mi!" gritaban las negras, disputándose las víctimas, ebrias de sangre como las mujeres que descuartizaron a Penteo.

La señal del ataque fue asaltar, saquear, y quemar el establecimiento del chino que había tenido la reyerta con la negra, como en aparente desagravio, pero en realidad, para probar a su gusto; algo parecido se intentó en Lima por el mismo populacho en la memorable noche que siguió a las derrotas de San Juan y Miraflores; por fortuna, acá con otros elementos de civilización propia y extranjera acumulad os, al desborde de la desnaturalización canalla fue sofocado ejemplarmente.

De El Pueblo (Pueblo Nuevo o Cañete) teatro del suceso, pasaron nuestro foragidos a la hacienda contigua de Montalván, que fue de O’Higgins, y a la también cercana de Gómez, valiosa, extensa y brillante propiedad de don José Unanue, el solo hijo varón del célebre sabio don Hipólito Unánue, dueño que fue de los terrenos de Gómez y de la hacienda de San Juan de Arona en Cañete.

El patio de la casa de Gómez sirvió de teatro a los mayores horrores en tre los que dejamos descritos; y cuentan que en la tarde de la matanza, un antiguo dependiente vascongado de la hacienda se ocupaba lúgubremente de espantar con un plumero las moscas que se cernían sobre los cad áveres amontonados. La casa antigua de Gómez fúe quemada y la moderna, una de las maravillas de Sudamérica como casa de hacienda, quemada tambiến en parte, las ricas puertas de caoba entallad a, los pisos de marquetería tuvieron el mismo fin, siendo destruido lo más En un momento desaparecieron por el incendio de Gómez, como 80 fanegad as de caña que equivalen a 40,000 quintales, igual 40,000 libras esterlinas sin perjuicio de los incendios paulatinos que se siguieron perpetrando por dos o tres años. El alzamiento de las turbas cañetanas no se dirigió exclusivamente sobre los asiáticos, sino sobre los blancos, sobre la propiedad, sobre la civilización.

Al mismo tiempo constituían los sublevados un pelotón en el puerto de Cerro Azul para recibir el vapor del Callao 18 chinos del lugar, que regresaban a sus hogares cañetanos después de haber hecho sus compras en Lima, y ajenos enteramente a lo que pasaba, fueron extraidos de la lancha a medio camino y echad os al agua atados de pies a manos. La negrada y la cholada festejaban su agonía, que no pudo ser muy lenta. Uno solo de estos desgraciados escapó, no sabemos por qué milagrosa circunstancia,

La última etapa de nuestros malhechores fue la hacienda de Casa-Blanca; los chinos de su dotación habían tenido tiempo, bien que cortísimo, para apercibirse de la defensa pasiva. Se encerraron y atrincheraron a gran prisa en número como de un mil, dentro del vasto edificio que contiene la Casa-Blanca con todas sus oficinas, almacenes y dependencias Los acompañaban algunos pocos compañeros de fuera que lograron huir y que comprendieron instintivamente que Casa-Blanca iba a ser el baluarte El número de chinos inmolados hasta entonces podía calcularse en mil y tantos.

Habria bastado un adarme de in teligencia y de calor para dar cuenta de ese ridículo sitio en media hora; pero la negrad a y la cholada está todavía más abajo de tan infimo nivel. El sitio duró cuatro meses; trajeron los sitiadores un cañoncito de a cuatro que yacía perdido en el pueblo de Mala, y del 
que tuvieron noticia; lo montaron con grandes precauciones, $y$ al primer disparo reventó o se sentó; fue abandonad o.

Los sitiados se defendían activamente; de los tubos de alambique y de las cañerías contrahacian armas de fuego, con las que efectuaban algunos tiros sobre los estúpidos sitiadores; también los ametrallaban lanzándoles botellas llenas de pólvora y fragmentos cortantes, y a las que ponían una mecha encendida. Con una especie de cañonazo que lograron disparar, hicieron tres víctimas en el campo enemigo.

Al fin, mediante una fuerte remuneración, consiguieron los hacendados que fuera a Cañete una fuerza chilena, los negros y cholos, duefios omnimodos de cuantiosas riquezas ajenas, de vid as y haciendas, huyeron despavoridos. El valle de Cañete, el opulento emporio de la caña de azícar, era un esqueleto que hasta hoy no ha vuelto a levantarse; sus florecientes trabajadores chinos habian regado con su sangre los mismos surcos que enriquecieron con el sudor de su frente.

Se abrieron las puertas de Casa-Blanca y empezó el éxodo de los nuevos Rodil, una procesión de fantasmas, de espectros lividos, de simulacros de hombres desfigurados por el hambre, los sufrimientos y el terror... se olvidó el asunto, si es que alguna vez se supo" 51 .

En este proceso de descomposición y conflicto se puede observar que las solidaridades étnicas se quiebran, a su vez, por la aparición de nuevos conflictos alimentados por oposiciones económicas y sociales en su interior. En suma, un entrecruzamiento múltiple en que las relaciones y oposiciones étnicas y de clase aparecen apoyándose mutuamente. Esta reversión que ocurre en el seno de los estamentos étnicos no es en realidad nada inusitado, pues desde largo tiempo atrás estos diferentes grupos estaban internamente diferenciad os. Su solidaridad, pese a estas brechas internas, era resultado de la explotación que los blancos ejercían sobre el conjunto de los grupos étnicos. El levantamiento de los "coolies" chinos ejemplificaba con bastante precisión estas oscilaciones sociales en la naturaleza del conflicto.

Un chino llamado Cheng Isao Ju escribió al Encargado de Negocios de Su Majestad británica William Barrington, pidiéndole averiguara si el Gobernador de Cantón estaría dispuesto a asegurar la custodia en Hong Kong y la remisión posterior a Cantón de diez secuestradores chinos, quienes en condición de prisioneros serían embarcados desde el Callao por la Legación china. En 1881 y 1882 , escribe Cheng Isao $\mathrm{Ju}$, estos chinos se habŕan dedicado al secuestro de sus propios compatriotas recurriendo a varias argucias para luego venderlos a los propietarios de diferentes haciendas peruanas. Esta venta de chinos oscilaba entre 3 y 4 mil. En 1883 y 1884, según el mismo Cheng, ellos cambiaron sus tácticas y se dedicaron a prestar dinero a los chinos para que se dedicaran al juego. Al no poder cancelar sus deudas, cerca de dos mil chinos se vieron 
obligados a venderse a sí mismos 52 .

A la movilización independiente de chinos y negros se añadió pronto el

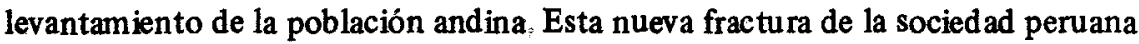
tuvo evidentemente un alcance más vasto, por el solo hecho de que la población india era numéricamente más importante que la de los otros grupos étnicos. De aquí también la preocupación de la clase dirigente por captar su adhesión, sentimiento simbolizado por la autoproclamación de Piérola como "Protector de la raza indígena" el 22 de mayo de 1880. Durante la Independencia, la población indígena había sido marginada en la construcción de la nación peruana; en 1879, se le convocaba para defender la patria en peligro. Luego de seis décadas, ¿era posible esperar que los indios pasaran de la exchusión al compromiso?

Entre 1879 y 1885 , al igual que en 1821 , la presencia india es innegable. Después de todo es imposible imaginar la constitución del ejército peruano sin el enrolamiento forzado de la población nativa. El sentido y los intereses que esta participación traduce son, sin embargo, problemas que requieren una indagación más cuidadosa. La caída de Lima y la destrucción del Estado oligárquico generaron entoda la zona andina diversos levantamientos de indios y cuyo desarrollo fue paralelo a las acciones militares desarrolladas por Cáceres y sus célebres "montoneras". Se ha mencionado ya que Cáceres asumió en las serranías andinas una heroica y admirable resistencia contra la ocupación chilena, en los momentos en que la oligarquía civilista debatra las condiciones de paz. En realidad, las "montoneras" caceristas constituyeron el encuadramiento militar relativamente ordenado de la población andina en contra de la ocupación chilena. Pero las acciones de los indios expresad as en movilizaciones independientes, o a través de las "montoneras" de Cáceres obedecen no sólo a los objetivos señalados por éste, sino que traducen también, o simultáneamente, reivindicaciones sociales y políticas mucho más concretas y que estaban referid as a su propia condición.

Al igual que los chinos y los negros, los indios de las serranías andinas constituían el segmento más explotado de la sociedad rural. Como comuneros, como siervos o como jornaleros agrícolas ellos generaron el excedente económico o brindaban la fuerza de trabajo necesarios al sostenimiento y a la reproducción del sistema de dominación regional. La profunda segmentación de esta población en diferentes unidades productivas había facilitado hasta aquel momento su control por la clase dirigente. Pero ahora la guerra no sólo dislocó estos lazos de poder y control, sino que estimuló la movilización de los indios. 
En efecto, la expoliación en contra de la población campesina en cada una de las correrías del ejército chileno, el arrasamiento de sus pueblos, los cupos de guerra impuestos, la destrucción de sembríos, la confiscación de ganado y bienes agravaron indudablemente la condición económica de esta población. Estos hechos actuaron como fulminantes adicionales para desencadenar y sostener su rebelión. Pero habra más. La defensa del país iniciada por Cáceres militarizó a los campesinos. Y estas armas no sólo estuvieron dirigidas contra los chilenos sino que naturalmente se volvierón también contra sus más antiguos y más directos opresores.

En agosto de 1882 el Cónsul inglés Graham informaba sobre el movimiento de los "montoneros" en los alrededores de Lima y el apoyo que recibían en sus acciones por parte de los indios. Estos últimos:

“... han sido llevados a la desesperación por ultrajes cometidos contra ellos por los invasores. Ahora se están muriendo de hambre, ya que todo el interior está devastado, haciendo imposible la siembra en este ańo, los granos, el ganado, el forraje y los animales, han sido tomados por una y otra parte" 53 .

En noviembre de 1883 Alfred St. John se referia igualmente a que "los indios en el departamento de Ayacucho se levantaron contra los blancos y están cometiendo atrocidades" 54 y que:

"La agitación entre los indios es atribuida al estado de anarquía que ha prevalecido en los Departamentos del interior durante los últimos tres años. Los cupos obligatorios exigidos por la expedición chilena también fueron una causa para el levantamiento en estos distritos.

No hay duda de que esta pobre gente ha sufrido muchísimo a lo largo de la guerra entre Chile y el Perú.

Obviamente aquellos acusan a las clases superiores del país de ser causantes de su infortunio, y tal vez sus quejas están bien fundadas en vista de que ninguno de los gobiernos anteriores hizo esfuerzo serio alguno para mejorar la condición de las razas indígenas" 55 .

Pero es al interior de la denominada "campaña de la Breña", admirablemente liderada por And rés A. Cáceres, en la que se pueden encontrar los indicios precisos sobre la naturaleza del comportamiento del campesinado andino durante la guerra con Chile. Apoyándome en un breve pero notable estudio del profesor Henri Favre sobre el conflicto de clases en el Perú durante este periodo, quisiera precisar el sentido de esta rebelión.

Andrés A. Cáceres probablemente nunca quiso que el movimiento de

53 M.E. Graham to Earl Granville. Lima, August 4th 1882, F.O. 61/340.

54 Alfred St. John to Earl Granville Lima, Nov: 13 th 1883. F.O. 61/348

55 Alfred St. John to Earl Granville. Lima, Dec. 3rd 1883. F O 61/348, 
resistencia que lideraba en contra de los chilenos, desembocara en una lucha social de naturaleza distinta. Su objetivo, al dirigirse a la sierra andina, era solamente diluir las fuerzas chilenas y obligarlas a combatir en un terreno mucho más propicio para sus "montoneras" $\$ 6$

Las guerrillas que se organizaron en el espacio formado por Huancavelica, Huanta y Huancayo, fueron básicamente campesinas y sus centros de encuadramiento fueron los pueblos de esta región. Etnicamente eran pueblos integrados por indios y por misti es decir, la población no india. Esta última no era homogénea, pero en todo caso una gran distancia la separaba de los terratenientes de la región. Arrojada en el seno de estos pueblos por las oscilaciones desfavorables de la coyuntura económica y política, la subsistencia del grupo misti dependía de la explotación de la población india o del ejercicio del comercio regional. Fue de este grupo de donde emergieron los jefes de la resistencia local, quienes, por el control económico y político que ejercían sobre los indios, pudieron rápidamente constituir las célebres "montoneras" que apoyaron a Cáceres. Su acción les permitía, a la vez, reforzar su autoridad sobre los indios y mejorar su posición frente a la capa de terratenientes de la región 57 .

Las guerrillas que ellos animaron, actuaron muchas veces con gran independencia de las decisiones del propio Cáceres, y, al mismo tiempo que combatian contra el ejército chileno, no vacilaron en tomar tierras, cosechas y ganado de los propietarios locales a fin de sostener la resistencia. En Colca, un pueblo en las alturas de Huancayo, la guerrilla local organizada por Tomás Bastidas, José Guerra y Manuel Echavaudis, tres poderosos misti del pueblo, procedió inmediatamente a la ocupación de la hacienda vecina "Tucle" 58 . Las fronteras de esta hacienda se habŕan extendido justamente a través de la anexión de las tierras del pueblo de Colca.

En 1882, nuevamente, la guerrilla toma las haciendas contiguas a $\mathrm{La}$ Virgen, Antapongo e Ingahuasi, liquidando de esta manera todo el sistema de latifundio de la región. Pero, observa Favre, la iniciativa de esta acción no correspondió más a los mistis sino a las tropas indias, quienes tienden así a emanciparse del control de los primeros. Frente a Bastid as, Guerra y Echavaud is, en efecto, emergen tres líderes indios, Laymes, Vílchez y Santisteb an, quienes conjuntamente con los otros guerrilleros indios, proceden al ataque y a la captura de las propiedades de losblancos y de los propios mis $t i^{59}$.

Henri Favre, "Remarques..." op.cit., p. 60.

57 Henri F avre, "Remarques..." op. cit., p. 69.

58 Henri Favre, "Remarques..." op.cit, , p. 69

59 Ibid, p. 62: 
Al año siguiente, 1883, las guerrillas indias alcanzan el dominio no sólo de Colca, sino del conjunto de la región central del Perú con la caída de Acostambo, el punto estratégico del área ${ }^{60}$, Huando, otro de los pueblos importantes, es totalmente vaciado de su población blanca ${ }^{61}$. Favre cita el testimonio escrito por un jefe chileno en noviembre de 1883 y cuya lectura muestra con elocuencia el significado profund o de la movilización de los indios:

"Todos los indios de Huanta y Huancayo, están sublevados. Los pocos con quienes pudimos entrar en contacto, declararon que su objetivo no era combatir a los chilenos, ni a los partidarios peruanos de la paz, sino toda la raza blanca" 62 .

El resultado de este levantamiento indio contra blancos y misti fue que toda la población no india, frente a la amenaza de sus vidas y de sus bienes, se inclinara por la colaboración con los chilenos, cuyo ejército representaba su única posibilidad de salvación ${ }^{63}$.

La guerra de razas, describe Favre, se prolonga hasta mediados de $1884 \mathrm{sin}$ que Cáceres, quien seguramente conocía su desarrollo y sus características, hiciera nada por reorientar la movilización de las guerrillas detrás de los objetivos inicialmente fijados. En febrero de 1884 incluso acusa al mist $i$ Tomás Bastidas de fomentar la discordia entre los patriotas, cuando éste buscaba desesperadamente retomar Colca y desarmar a los perseguidores de Laynes ${ }^{64}$. Las razones de la actitud de Cáceres frente a los indios, en esta coyuntura específica de la guerra, qued a abierta a la explicación histórica.

Con el eclipse de la guerra, la resistencia contra Chile perdió obviamente su sentido, pero ello no significaba la contención del movimiento campesino. Más bien lo impulsó en algunas regiones. Cáceres, por su parte, aspira al control polftico del Estado y rápidamente logra el apoyo de la clase dirigente, cuyos miembros ven en él al militar con el suficiente prestigio y poder como para restablecer el orden. Aqui el problema es cómo se frenó la acción de las "montoneras" directamente lideradas por Cáceres. En el ceso de Colca, Favre indica que la resistencia de las "montoneras" termina con la captura de sus lideres. En junio de 1884, Laymes, Vilchez y Santisteban fueron convocad os a Huancayo para recibir de manos de Cáceres la recompensa por su comportamiento durante la resistencia. Pero a su regreso a la ciudad fueron capturados por una unidad del ejército regular, juzgados sumariamente por una corte marcial y fusilados en la Plaza de la Catedral ${ }^{65}$. Cáceres, en una carta citada por Favre,

Ibid.

Henri Favre, "Remarques ..." op.cit., p. 63.

Ibid., p. 64.

Ibid.

65 Henri F avre, “Remarques ...” op.cit., pp. 64-65. 
justifica el hecho diciendo lo siguiente:

"Estos individuos, olvidadizos de la noble misión que debían cumplir, lejos de garantizar la vida y los bienes de la población cometieron horribles asesinatos, incendiaron y saquearon pueblos enteros, ejercieron terribles venganzas personales. .. la misma monstruosidad de sus crímenes que se denunciaba, me hacía dud ar de su realidad y me obligaba a reunir todas las pruebas de acusación" 66 .

El viraje de Cáceres contra sus antiguos seguidores era apenas el preludio de cambios más sorprendentes en la actitud de este militar. Como si el Perú de estos tiempos no estuviera dispuesto a perdonar gestos como el suyo y como si fuera necesario cobrarle la revancha por su indomable resistencia, por una de esas crueles ironías que sólo la historia conserva el secreto, el mismo Cáceres se vió, en efecto, obligado poco más tarde, a pactar con la clase dirigente, es decir, con aquella que habia sido también el blanco de sus ataques durante la guerra con Chile. Y por si esto fuera poco, él, quien habra sido precisamente el terco defensor de la integridad del territorio, tuvo que firmar el célebre contrato Grace que consolidaba la colonización económica del Perú, luego de haber soportado un intenso debate de tres años y haber expulsado del Parlamento a todos sus oponentes.

La desmovilización de la población campesina en otras áreas del interior peruano no fue, sin embargo, tan fácil como habla sido en esta región. La proclamación de Iglesias como "regenerador" de la República en diciembre de 1882, el retiro después del Tratado de Ancón de las fuerzas chilenas que eran el sustento militar de este gobiemo y la abierta disputa por el poder entre Iglesias y Cáceres hasta 1886, eran procesos decisivos que en nada facilitaban la reimposición de un control social sobre la población indigena. El retiro de las fuerzas chilenas, sobre todo, fue percibido con un particular espanto por la clase propietaria, ya que los soldados chilenos habían sido durante estos años de crisis los únicos garantes de sus bienes, frente al ataque de las masas populares. Ante la desorganización del ejército peruano, las tropas chilenas eran igualmente la única fuerza de contención a la movilización campesina. Es por esto que paralelamente al retiro de ellas, el levantamiento de los campesinos adquiere mayor intensidad y amplitud. Aquí sólo quisiera citar algunos ejemplos.

En abril de 1884 Nemesio Viaf́a encabezó en Cerro de Pasco un levantamiento de 400 indios aprovechando que el Prefecto del departamento Pedro Más y una tropa de 200 soldados abandonaron la ciudad para ayudar al sofocamiento de una rebelión en Huánuco ${ }^{67}$. Viaña se levantó en nombre de

67 Gro, E. Steel to Alfred St. John. Cerro de Pasco. April 12th 1884. F. O, 177/182. 
Andrés A. Cáceres, mientras que Más era uno de los Prefectos designados por Iglesias. El levantamiento fue muy breve y terminó con la derrota del primero ${ }^{68}$ En mayo de $1884 \mathrm{e}$ campesinado andino se rebeló en la provincia de Huánuco, mientras que los "montoneros" tomaban Chincha Alta ${ }^{69}$. Un mes más tarde, junio de 1884, levantamientos similares ocurrían en el Cuzco, en Vilcabamba (Junín) en Cajamarca ${ }^{70}$. En agosto del mismo año, finalmente, Puga y sus "montoneros", después de consolidar su poder en Cajamarca, pasaron a ocupar Lambayeque extendiendo asi su dominio al conjunto del norte peruano ${ }^{71}$. En suma, la profunda debilidad del gobierno de Iglesias y la ausencia de todo control por el retiro sucesivo del ejército chileno, generaron una revuelta generalizada a lo largo de todo el país. Alfred St. John constata en efecto:

"Este país está completamente sumergido en la anarquía, y todos sienten que la autoridad del General Iglesias sólo durará mientras esté apoyada por las bayonetas chilenas" 72 .

No se conocen desafortunadamente las condiciones precisas en que una nueva pax andina fue impuesta al campesinado rebelde. Pero, en cambio, es posible argumentar sobre las consecuencias que tuvo la guerra sobre el campesinado andino. En la guerra con Chile el campesinado andino aprendió, aunque seguramente de una manera todavía errática, a tomar conciencia de su situación y establecer lazos de solidaridad más amplios que los impuestos por los estrechos marcos de sus comunidades trad icionales. Es esta toma de conciencia la que llevó, por ejemplo, a los asentamientos dispersos de las altas punas de Huancavelica, surgidos como respuesta al incremento demográfico y al fraccionamiento de la propiedad de la tierra en las comunidades de los valles, a organizarse y a romper los nexos de subordinación que mantenían con estas últimas, es decir, con comunidades enteramente dominadas por los blancos $\cos ^{73}$. En esta toma de conciencia, también la que alentó más tarde el extraordinario movimiento liderado por Atusparia, el Alcalde de Indios de Huaraz, en la sierra norte, movimiento que por otra parte no es sino el preludio del renacimiento

68 "Suplemento al Registro Oficial No 13".Cerro de Pasco 9 de abril de 1884. F.O. 177/182.

69 Alfred St. John a Earl Granville. Lima, May 7th 1884. F.O.61/353.

$70 \quad$ Ibid., June 5 th 1884 . F.O.61/353.

71 Bristish Vice Consul to William Barrington. Lambayeque, August 16 th 1884, F O. 177/182.

72 Alfred St. John to Earl Granville. Lima, June 5th 1884, F O. 61/353

73 Henri Favre, "La crise de la société paysanne et la migration vers les peantations cótierés dans le Pérou central". In Kenneth Duncan y Ian Rutledge (eds) Land on Labor in Latin America: Essays on the Development of Agrarian Capitalism in the Nineteenth and Twentieth Centuries, Cambridge, 1977, pp 253267 y pp 259260 
de un fantástico ciclo de revueltas campesinas que atraviesa el centro y sur del Perú.

Frente al contacto directo y desnudo de la agresión y expoliación impuesta por el invasor extranjero, la conciencia hasta entonces étnica del campesinade andino empezaba tal vez a transformarse en un sentimiento de solidaridad nacional frente al destino común de un pueblo por ahora vencido. "Y como oí que todos se llamaban peruanos, yo también me llamé peruano... Aprendí que Perú es una nación y Chile otra nación", es la expresión patética del indio Aparicio Pomares en el relato de Enrique López Albújar.

En las páginas anteriores se ha tratado de mostrar de la manera más precisa posible el impacto de la Guerra del Pacf́fico en la descomposición interna de la sociedad peruana. Ahora, a manera de epílogo y para trabajos posteriores, es conveniente dejar anotadas algunas reflexiones sobre el significado de este conflicto en la posterior historia económica y política del Perú contemporáneo y sobre el nuevo carácter que paralelamente revisten las relaciones étnicas y de clase. A falta de indicadores más precisos, las notas escritas por Clavero en 1896 permiten una primera evaluación del impacto del conflicto en la estructura interna de la sociedad peruana. Sus observaciones están resumidas en el cuadro siguiente:

1970

Millonarios

ricos

acomodados

mendigos

obreros

\section{0}

Millonarios
ricos
acomod ados
mendigos
obreros

$\begin{array}{rc}18 & -- \\ 11,587 & 1,725 \\ 22,148 & 2,000 \\ -- & 500,000 \\ 1^{\prime} 236,000 & 345,000^{74}\end{array}$

La palabra "colapso" es probablemente la que mejor expresa la situación del Perú después de la guerra, colapso, en este caso, traducido en una alteración significativa de la estratificación social. No es otro el significado de la desaparición de la cúpula oligárquica y el tremendo incremento en la pauperización de las clases populares. A este cuadro de base se añade la práctica paralización de la economfa peruana inmediatamente después de la guerra. Se sabe, en efecto, que el valor de las importaciones en 1885 ascen'ía a 8' 181,000 , mientras que las exportaciones sólo llegaban a 2'400,000 soles ${ }^{75}$. Pero aquello

74 José Clavero, El tesoro del Perú, Lima, 1896, p. 51.

75 Jorge Basadre, Historia de la República del Perú, 5a ed., 10 vols., Lima, 1962-64, VI: 2695. 
no era todo. La crisis política nacida por la destrucción del control y del Estado oligárquico, coronaba el desequilibrio social y el estancamiento de la economía peruana.

La forma como el Perú se "reconstruye", es decir el nuevo alineamiento interno de sus diferentes fuerzas sociales, así como la nueva naturaleza que reviste su inserción en el mercado internacional, hacen de los años inmediatos de la postguerra el punto de partida del ordenamiento del Perú contemporáneo. Brevemente, la recuperación de la economía peruana fue el resultado de tres procesos convergentes: la monopolización de los recursos, su desnacionalización y el flujo creciente, bajo nuevas modalidades operativas, del capital extranjero. La creación de la Penuvian Corporation en 1890, al cancelar la deuda externa peruana mediante la entrega a los tenedores de bonos ingleses de los principales recursos productivos del país, es el acto obligado que permite la recomposición económica del Perú. Salvo algunas pero poco significativas excepciones, los enclaves imperialistas se convierten así en los agentes del reactivamiento de la economía peruana. Ellos canalizan las inversiones directas del capital extranjero hacia la explotación de los principales recursos naturales y configuran los nuevos espacios económicos. Se crean de esta manera las bases para la explotación intensiva del azúcar, cobre y petróleo.

De manera paralela a la reconstrucción de la economía peruana, se hizo necesario proceder al reordenamiento institucional de la sociedad y al restablecimiento de un control político que fuese compatible con las nuevas exigencias de la economía internacional. Pero esta vez el proceso político fue menos lineal y la década entre 1885 y 1895 es apenas el inicio balbuceante de una solución definitiva.

La guerra no sólo habfa volatilizado toda la estructura del control impuesta por la oligarquia civilista, sino que la había dejado en absoluta incapacidad para restablecer su dominio. Después del Tratado de Ancón y hasta 1886 son Miguel Iglesias y Andrés A. Cáceres, dos militares, quienes se disputan el poder político. Para la oligarquía civilista, luego de su desencanto con Iglesias, era Cáceres el único caudillo con el prestigio y la autoridad suficientes como para imponer el orden interno necesario al restablecimiento de sus negocios. Pese a que sus miembros habran sido combatidos por el mismo Cáceres durante la guerra, no vacilaron en apoyar su gobiemo en función de estas exigencias materiales. Es este pacto, renovado en 1890 , que le permitió a la oligarquía civilista el espacio necesario para su restablecimiento como clase y para prepararse para compartir el poder, en 1895, con Nicolás de Piérola, es decir, con otro de sus más decididos adversarios.

Pero si bien la reconstrucción económica y política apuntaba de un lado hacia la estabilidad del sistema, no podían dejar de generar efectos contrarios. En 
efecto, una nueva pax andina en el seno del campesinado fue la más difícil de obtener. La guerra con Chile hab ía permitido una impresionante movilización del campesinado andino, la cual además se habỉa intensificado a medida que las tropas chilenas abandonaban el territorio peruano. La reconstitución del caciquismo regional significó la represión de estas rebeliones andinas, pero aquella fue una victoria muy precaria. La casi inmediata implantación de los "enclaves" capitalistas en la mineria y la agricultura, al proletarizar y pauperizar a segmentos importantes de la población campesina, volvió a encender las llamas de la rebeldía en las brasas aún humean tes dejadas por el conflicto del 79. Pero lo que en adelante producirá este fulminante serán rebeliones campesinas más que rebeliones de indigenas Por si esto fuera poco, el conflicto con Chile al revelar lo que Gonzales Prada llamara "las llagas purulentas" de la sociedad peruana, inspiró el nacimiento de las ideologías radicales que cuestionarán la esencia y la legitimidad de la dominación oligárquica. 